\title{
Guidelines for the training of general psychiatrists in child and adolescent psychiatry
}

\author{
The following guidelines were drawn up by the \\ Executive Committee of the Child and Adolescent \\ Specialist Section and were approved by the \\ Court of Electors.
}

\section{Introduction}

1. These guidelines concern training in child and adolescent psychiatry during the three years of general professional training, preceding the MRCPsych examination. It is a modified version of a previous College paper on the subject (1979). Consideration is not given in this memorandum to specialist training in child and adolescent psychiatry which starts at senior registrar level. The basic requirements for specialist training were set out in the "Memorandum on training in child and adolescent psychiatry' published in 1973.

2. It is desirable that child and adolescent psychiatry be an integral part of every trainee's experience and that training be of high quality.

3. Child and adolescent psychiatrists are based in hospitals or child guidance clinics. Valuable experience of the subject could be obtained in either of these locations.

4. There are many aspects of psychiatry which become very evident in child and adolescent psychiatry which are of general educational value such as an intimate knowledge of recent child development, and a contemporary view of the tensions in a family.

\section{Proposals for training}

\section{Educational objectives}

In general terms the educational objectives are:

i. to provide a sound basic knowledge of theories of child development and psychopathology and the evidence supporting these theories; the prevalence, natural history and clinical features of common disorders presenting in children and adolescents; classification systems; theories of child-parent and family interaction; methods of treatment; and the range of services available;

ii. to promote the acquisition of the clinical and therapeutic skills necessary to conduct the assess- ment and management of children and their families. Emphasis needs to be placed on diagnostic assessment of skills which enable the trainee to construct a multidimensional formulation, understanding the interplay between emotional, physical, developmental, intellectual, social and educational components. The skills required in liaison and consultation form an essential part of management. Trainees can acquire consultation and liaison skills as part of supervised collaboration with a range of medical and non-medical professional staff in social services, education and health departments;

iii. to develop the trainees' perceptiveness and sensitivity to the communications of children, adolescents, parents and families;

iv. to generate appropriate attitudes that enable trainees to co-operate appropriately in multidisciplinary teams.

\section{Teaching methods}

The following methods are recommended:

\section{i. Supervised clinical experience}

a. Training is best undertaken under supervision by a senior child psychiatrist or staff member working in a clinic with access to full medical investigatory facilities and where there is access to the various settings available to disturbed children and adolescents. In principle, all consultants should accept responsibility for training registrars.

b. Ideally general trainees should obtain six months' full-time clinical experience in a service for children or adolescents. An alternative would be 12 months part-time training. However, brief attachments, such as one or two sessions per week in a limited period allow the trainee to be a passive observer and are to be discouraged.

c. There should be experience of work with children and adolescents as out-patients or in in-patient or residential care settings.

d. All training should take place as a member of a clinical team and, preferably, in contact with trainees from other professional disciplines such as social work, psychology and child psychotherapy.

e. Clinical experience should cover a wide or possible range of clinical problems and treatment 
techniques, including the problems of mentally handicapped children. There should be exposure to a variety of theoretical orientations and exponents of different sorts of treatment including individual and family therapy. The trainee should become familiar with the range of community services available including visits to penal and social service provisions. Liaison work with paediatricians should be undertaken wherever possible.

\section{ii. Theoretical instruction}

a. A course of lectures forming part of a dayrelease programme, organised regionally, provides a systematic introduction to the field and should form the core of formal training.

b. Seminar-tutorials, small group discussions, case conferences and journal club meetings need to be organised in a planned way, preferably arranged on a multidisciplinary basis.

c. Meetings concerned with child psychiatric topics should feature regularly in the programme of activities arranged for all general trainees, throughout the period of general professional training required for the MRCPsych.

d. The library must provide an adequate supply of books and journals concerning child, adolescent and family psychiatry.

\section{Organisational requirements}

i. These training programmes in child and adolescent psychiatry require experienced teachers and their implementation calls for major investment of time and energy by consultants and the other members of multidisciplinary teams. Furthermore, in some clinics, full introduction of these recommendations may call for the provision of additional staff time.

ii. Intermittent attachments make the case load of hospitals and clinics difficult to cope with. The development of training in small clinics may generate problems if there is not a constant flow of trainees. iii. Child psychiatrists should be invited to committees selecting trainees.

iv. Some trainees wish to acquire more than the minimum of six months' experience in child and adolescent psychiatry and exceptionally, it should be possible to offer a post of a year's duration in child psychiatry to some trainees to assist them in making a decision about specialising before completing the MRCPsych examination.

v. Placements should not normally occur until after at least 12 months experience in psychiatry.

\section{Specific recommendations}

i. In their consideration of general professional training programmes, Visiting Approval Panels should enquire fully into the availability and quality of training in child and adolescent psychiatry. Approval should not be given to posts for general professional training without careful consideration of the child psychiatry training in the locality. Child psychiatrists with experience of training programmes should be members of the Approval Panels.

ii. In all training schemes incorporating placement in child psychiatry departments, a representative consultant child psychiatrist should be involved actively in the selection procedure. In this way suitability for training in the child and adolescent psychiatry field could be given due consideration.

\section{References}

The Royal College of Psychiatrists (1973) Memorandum on training in child and adolescent psychiatry. News and Notes, April, 5-8.

RMPA (1970) The training of psychiatrists. British Journal of Psychiatry. Special Publication No. 5.

Royal College of Psychiatrists (1978) The role, responsibilities and work of the child and adolescent psychiatrist. Bulletin, July, 127-131.

- - (1979) Guidelines for the training of general psychiatrists in child and adolescent psychiatry. May.

Hill, P. \& Cotrrell, D. Child and adolescent psychiatry for the future general adult psychiatrist (in press).

February 1988

\section{Correction}

The document 'The Role, Responsibilities and Work of the Consultant Forensic Psychiatrist' (Bulletin, June $1988,12,246-249$ ) is not, as previously stated, a discussion document but was approved by Council on 16 March 1988. 